\title{
Long-Term Treatment with Antithyroid Drugs: Efficacy and Safety
}

\author{
Ramin Malboosbaf ${ }^{1}$ and Fereidoun Azizi ${ }^{2, *}$ \\ ${ }^{1}$ Endocrine Research Center, Institute of Endocrinology and Metabolism, Iran University of Medical Sciences, Tehran, Iran \\ ${ }^{2}$ Endocrine Research Center, Research Institute for Endocrine Sciences, Shahid Beheshti University of Medical Sciences, Tehran, Iran \\ "Corresponding author: Endocrine Research Center, Research Institute for Endocrine Sciences, Shahid Beheshti University of Medical Sciences, P.O. Box: 19395-4763, Tehran, \\ Iran. Tel: +98-2122409309, Fax: +98-2122402463, Email: azizi@endocrine.ac.ir
}

Received 2020 February 17; Revised 2020 April 27; Accepted 2020 May 02.

\begin{abstract}
Context: Medical therapy of hyperthyroidism has been the Astwood's gift to medicine. However, controversy remains about its mechanisms of action, the ideal treatment duration, and its proper use in pregnancy. The concept that hyperthyroidism could be controlled 'indefinitely' with antithyroid drugs (ATDs) is also a topic of current debate. The purpose of this review was to highlight the pros and cons of long-term ATD therapy.

Evidence Acquisition: PubMed, Scopus, Web of Science, and Google Scholar databases were searched for retrieving studies conducted on long-term treatment with ATDs up to Jan 2020. The final selection of the papers was made based on their relevancy with the safety and efficacy of long-term treatment with ATDs.

Results: The main drawback of the ATD treatment is the high relapse rate after drug discontinuation. On the other hand, ATDs may have a favorable immunosuppressive effect, either primarily, in the diminution of thyroid-specific autoimmunity, or secondarily, as a result of controlling the hyperthyroid state, hence keeping patients in a euthyroid state for a prolonged period to diminish autoimmunity and hyperthyroid relapse. This often calls for long-term use of methimazole, but with the lowest possible dose to minimize the risk of side effects. Emerging evidence demonstrates that the long-term treatment with ATDs has relatively few adverse events, most of which arise within the starting months of treatment and in subjects on larger doses. Hence, once we have reached the end of a conventional course of ATD treatment (12 - 18 months), the hazard is eliminated, and adverse events are very rare to occur. Therefore, by continuing low-dose ATD, we could safely maintain the patient's euthyroid status.

Conclusions: Long-term ATD treatment is safe, especially at a low dose. It can be considered as the preferred treatment for selected hyperthyroid patients.
\end{abstract}

Keywords: Methimazole, Graves' Disease, Propylthiouracil, Antithyroid Drugs, Long-Term Therapy, Continuous Therapy

\section{Context}

Medical therapy of hyperthyroidism has been the Astwood's gift to medicine. However, controversy remains about its mechanisms of action, the ideal treatment duration, and its proper use in pregnancy. The concept that hyperthyroidism could be controlled 'indefinitely' with antithyroid drugs (ATDs) is also a topic of the present debate. The purpose of this review was to highlight the pros and cons of long-term treatment with ATDs.

\section{Evidence Acquisition}

PubMed, Scopus, Web of Science, and Google Scholar databases were searched for retrieving studies conducted on long-term treatment with ATDs up to Jan 2020. The final selection of the papers was based on their relevancy with the safety and efficacy of long-term treatment with ATDs.

\section{Results}

\subsection{Introduction}

Before the 1940s, the sole therapy for hyperthyroidism was surgery. In 1942, Edwin B Astwood started sequences of experiments that would eventually result in the birth of what he called ATDs (1). Interestingly, many of the Astwood's findings, after over seven decades, remain highly controversial, e.g., Astwood was the first to report the adverse effects of ATDs, mainly skin rash and agranulocytosis $(2,3)$, and the possibility of their use during pregnancy $(4)$; both are still debated topics. Astwood's group described that some patients had long-lasting 'remissions' after a prolonged course of therapy (5). The concept that Graves' disease (GD) might be restrained 'infinitely' with ATDs is also a current topic of debate; this was documented 60 years ago when Astwood reported 16 years of treatment in some patients (6). 


\subsection{Mechanism of Action}

\subsubsection{Inhibition of Thyroid Hormone Synthesis}

'Thionamide', a class of ATDs, are thiourea derivatives that are five- or six-membered ring structured sulfurcontaining compounds. Its main effect seems to be the inhibition of the 'organification' of inorganic iodine. Also, it has been suggested that ATDs inhibit the coupling reaction (7). Propylthiouracil (PTU) decreases T3 formation from T4 in peripheral tissues by inhibiting the selenoprotein, type I iodothyronine deiodinase (8). Although this requires high doses of PTU, it is not usually employed in clinical practice.

\subsubsection{Effects on Thyroid Autoimmunity}

The effects of ATDs, whether direct or indirect, on thyroid autoimmunity have been interesting (9). Some in vitro clues show that thionamide ATDs might have direct effects on intrathyroidal T cells $(10,11)$ and HLA Class II expression by thyrocytes (12), as well as in vivo effects for increasing suppressor $\mathrm{T}$ cells and decreasing intrathyroidal activated T cells (13).

On the other hands, it is also believed that the indirect effects on the immune system, as a result of controlling the hyperthyroid state, are much more important than the direct effects of thionamides on thyroid autoimmunity (14, $15)$; it is unclear which, if any, of these effects is the main effect of ATDs on the immune system in reducing antiTSH receptor antibody (TRAb) and ensuing remission.

\subsubsection{Antioxidant Activity}

Production of superoxide radicals is enhanced by the increased basal metabolic rate associated with hyperthyroidism $(16,17)$. A clinical study has shown that free radical scavengers, plasma thiol levels, and superoxide dismutase activity were decreased in thyrotoxicosis, but normalized after CBM treatment (18). Another study revealed that antioxidants (vitamin E and coenzyme Q10) were decreased, whereas indices of lipid peroxidation were increased in untreated GD, but normalized after ATDs treatment(19). None of these studies could differentiate the effects of the ATDs from the effects of correcting hyperthyroidism per se.

\subsection{Clinical Implications}

\subsubsection{Restitution of Euthyroidism}

Three available ATDs are methimazole (MMI), PTU, and carbimazole (CBM). CBM is a prodrug for MMI, with $10 \mathrm{mg}$ CBM, making about $6 \mathrm{mg}$ MMI (20). CBM/MMI can be given as a single daily dose. PTU is the least potent ATD (100 mg $\mathrm{PTU} \approx 5 \mathrm{mg} \mathrm{MMI}$ ) and has the shortest duration of action, typically initiated three times daily. CBM/MMI is the preferred ATD because of its superior efficacy, its once-daily dosing regimen, and fewer adverse events $(21,22)$. Severe hepatic complications of the PTU have ruled out its use as the first choice in hyperthyroid treatment, in particular in pediatric patients. Nevertheless, PTU is the first choice of treatment during the first trimester of pregnancy because of a lower prevalence and severity of drug-associated embryopathy compared with $\operatorname{CBM} / \operatorname{MMI}(23,24)$ and in the management of thyroid storm, thanks to additional inhibition of T4-to-T3 conversion $(25,26)$. The starting dose of $\mathrm{CBM} / \mathrm{MMI}$ should be determined by the severity of hyperthyroidism. Recommended starting doses of ATDs based on the degree of elevation in free T4 by the American Thyroid Association (ATA) guidelines (2016) for the management of hyperthyroidism are illustrated in Table 1(21).

\begin{tabular}{|c|c|c|c|}
\hline $\begin{array}{l}\text { Free T4 Elevation }(\times \text { Upper } \\
\text { Limit of Normal) }\end{array}$ & CBM (mg) & MMI (mg) & PTU (mg) \\
\hline 1- 1.5 & $10-15$ & $5-10$ & $100-200$ \\
\hline $1.5-2$ & $20-30$ & $10-20$ & $200-400$ \\
\hline $2-3$ & $50-70$ & $30-40$ & $600-800$ \\
\hline
\end{tabular}

Abbreviations: CBM, carbimazole; MMI, methimazole; PTU, propylthiouracil. Adopted from reference 21 .

ATDs are almost completely absorbed after oral administration, with peak serum levels achieved within 1 - $2 \mathrm{~h}$ with gradual restitution of euthyroidism. After 3 months of treatment with MMI, euthyroidism is achieved in almost all patients ( 95\%); however, this rate will be lower $(\sim 70 \%)$ in severe hyperthyroidism and cases treated with PTU (27, 28).

\subsubsection{Remission from Graves' Disease}

Remission has been defined as euthyroidism for at least one year after discontinuation of ATDs (21). Almost one-half of patients can go into remission following one year of ATD treatment, a rate that varies from 30\% to $70 \%$ based on clinical and geographical parameters (29). Although relapse of hyperthyroidism occurs in one-third of patients achieving remission, almost one-third of patients possibly go into permanent remission (30). Pathogenesis and mechanisms involved in the recurrence of GD are not clear and must be carefully studied.

Several studies have assessed the patient's factors and regimes of ATD treatment predictive of remission. The most consistent features predicting relapse are larger goiter (30-35), smoking $(33,35-38)$ and the postpartum state $(39,40)$. Other likely factors are younger age $(30,32)$, male gender $(30,32,41)$, the severity of hyperthyroidism at diagnosis (42), Graves' orbitopathy (43), and genetics (32, 44).

At an individual level, none of the possible risk factors for relapse has sufficient sensitivity and specificity to pre- 
dict recurrences (45). Recently, a group from the Netherlands developed two predictive scoring systems for the recurrence of GD after a course of treatment with ATDs (44). The first, named the Graves' Recurrent Events After Therapy (GREAT) score, is based on clinical (age) and biochemical variables (serum fT4 and TSH-binding inhibitory immunoglobulins [TBII]) before the initiation of the ATDs, and the second, the GREAT+ score, is an enhanced predictive score, which combines genetic markers in addition to the clinical and biochemical parameters used in the GREAT score. The GREAT score, but not the GREAT+, has been externally validated by studies conducted in Swiss (46) and Italia (47). Limitations of the present study are the relatively low number of male patients, possibly preventing the detection of the male sex as a determinant of recurrence. Also, most severe hyperthyroid patients and those with large symptomatic goiter were treated directly with surgery or radioiodine therapy (44). The GREAT+ score in common clinical practice might be limited due to is cost and unavailability of genetic testing (44). On the other hand, a genetic predisposition for GD has not yet been fully elucidated, and studies conducted in different ethnic populations with different research methodologies have reported conflicting results regarding the genetic predictors for the recurrence of GD (48).

The optimum duration of ATD treatment is $12-18$ months, while short ( 6 months) treatment courses are associated with a high recurrence rate $(22,49)$; the underlying mechanisms for remission induced by ATDs are still uncertain. As mentioned before, besides the potential direct immunologic effects of ATDs, euthyroidism attainment without ATDs (such as perchlorate or thyroid surgery) appears to have favorable immune effects, as shown by decreases in TRAb levels (15).

A major shortcoming in this area is the inability of available TRAb assays to predict remission and recurrences of GD. Typically, after 18 months of MMI treatment, serum TRAb levels are significantly lower than baseline. Although $65 \%$ - 75\% of these cases have positive TRAb values; $40 \%$ $80 \%$ of them will have a relapse of hyperthyroidism after ATD cessation $(50,51)$. Even using the second generation TRAb assay, with higher sensitivity and specificity, the predictive value for relapse is still controversial (50). Although negative TRAb assays at the end of an ATD course cannot rule out the recurrence of hyperthyroidism, the persistent positivity of TRAb assays is a strong predictor of relapse and would guide the clinician to continue ATD treatment beyond the common course of 18 - 24 months or switch to ablative therapy (RAI or thyroidectomy) (45).

\subsection{Long-Term ATD Therapy}

The 2016 ATA guidelines propose that continuous ATDs treatment is a rational alternate for ablative therapy (RAI or thyroidectomy) in patients who could not attain remission following the first course of treatment with ATDs (21). Other studies suggest continuous ATD treatment in wellcontrolled mild GD $(21,52)$ or giving long-term ATD (for years or even for a lifetime) until TRAbs disappear $(53,54)$. However, long-term ATD therapy could become a more commonly accepted approach in young and middle-aged patients, particularly considering recent data on the adverse effects of RAI on the quality of life $(55,56)$ and increased mortality from breast cancer and all solid cancers (57).

Advocates of continuous low-dose ATD treatment emphasize on increasingly patients' preference for nonablative therapy (58) and low incidence of adverse events $(28,59)$, which mainly occur within the first 3 months of therapy (60); opponents highlight the needs for a serial reassessment of dosing adequacy and possibly rare lateoccurring adverse events, such as vasculitis (61).

It has been suggested that long-term ATD therapy is effective and safe both in adults $(54,62,63)$ and in children and adolescents (42, 63-68). Comparing 10-year outcomes, in patients who could not attain remission on ATDs, continuous low-dose ATD treatment had lesser episodes of hypothyroidism and slightly fewer costs than RAI therapy (54). A second study by the same author reported that continuous low-dose ATD treatment was safe and had fewer events of subclinical hypothyroidism and dyslipidemia compared with patients on levothyroxine replacement for RAI-induced hypothyroidism. Also, parameters, such as echocardiography findings, bone mineral density (BMD), and neuropsychology tests favor MMI treatment over RAI (55). Another study (61) evaluating long-term ATDs treatment in patients with Graves' orbitopathy, using a blockand-replace regimen, reported that $90 \%$ of the patients remained continuously euthyroid during a mean follow-up of 6.7 years; adverse events were rare, including five skin reactions to MMI and one vasculitis with PTU (61). Yet another study reported a remission rate of $63 \%$ in GD patients subjected to long-term treatment with $\operatorname{ATD}(2-11$ years $)$ and then followed for an average of 4.5 years after stopping ATD (59).

A retrospective study showed that continuous lowdose ATD treatment had better preservation of euthyroidism, lower weight, gains, and orbitopathy worsening than those treated with RAI (69). A recent study on the treatment of toxic multinodular goiter showed that longterm, low-dose MMI treatment for 60-100 months not only is safe and effective but is in no way inferior to RAI. The adverse effects of MMI occur in the first three months of 
treatment. Three out of 65 patients developed skin reactions and were subjected to treatment with PTU, whereas one had an elevation of liver enzymes and chose radioiodine therapy (70).

A systematic review and meta-analysis of studies, in which Graves' hyperthyroidism had been treated with ATD for $\geq 2$ years, found a remission rate of $57 \%$ (38) and the annual remission rate of $16 \%$; however, it should be noted that this is not a true linear correlation, although a positive relationship can be suggested between time and remission rate (38). The 2016 ATA guidelines propose that treatment with ATD for more than 12 - 18 months is a suitable option in patients preferring this approach (21).

The conflict regarding how long ATD should be used in children before considering either RAI or surgery is still a topic of controversy, warranting further research (21). The persistence of GD in children is correlated with the persistence of TRAb. It appears that TRAb levels persist longer in children than in adults (71). However, monitoring TRAb levels while on ATD has been shown to be useful in adult patients for predicting the likelihood of remission or relapse of GD after discontinuing medication (72), an approach, which has yet to be validated in children (21). If remission is not achieved following stopping MMI after at least 1 or 2 years of therapy, RAI or surgery should be considered, depending on the age of the child (21). Alternatively, practitioners can continue MMI for extended periods, as long as adverse drug effects do not occur, and the hyperthyroid state is controlled (21). As already noted, adverse reactions typically occur within the first few months of therapy (21). Individuals on prolonged ATD therapy $(>2$ years) should be reevaluated every $6-12$ months and while transitioning to adulthood (21). A recent study on juvenile GD demonstrated that long-term (96 - 120 months) MMI treatment is safe and effective. The four-year cure rate of hyperthyroidism was nearly 3 times more than that of short-term treatment (73). Another prospective report from France shows that with prolonged ATD use, remission rates of up to $49 \%$ could be achieved (42); the use of MMI in this group of children was associated with a very low rate of adverse effects (42). Thus, although many practitioners will consider a trial of MMI for 1 or 2 years, these data suggest that treatment for longer periods is also reasonable, as long as side effects to medication do not occur (42). Long-term MMI therapy was recommended for all juvenile hyperthyroid patients because of the low incidence of adverse events in small doses of ATDs and a clinical impression that euthyroid patients on ATDs have fewer complaints than those on levothyroxine (74).

\subsection{Adverse Events}

In general, adverse effects of ATDs can be divided into common, minor cutaneous allergic side effects and rare but serious allergic/toxic events, such as agranulocytosis, hepatic damage, or vasculitis. Adverse events are mainly observed within the first 3 months of therapy (60), but rare late-occurring adverse events, such as vasculitis can also $\operatorname{occur}(61)$.

There is a small but growing number of studies on long-term treatment with ATD in patients with GD. One systematic review and meta-analysis of trials with a minimum of two years of ATD therapy demonstrated an overall adverse events rate of $19.1 \%$, including mostly rash, gastric intolerance, or arthralgia, and only severe reaction rate of 1.5\% (38). Another systematic review (75), including data from 1,660 patients treated with ATDs for a mean duration of 5.8 years (2.1 to 14.2 years) (around 10,000 patientyears), reported major complications only in 14 patients; i.e. 7 cases of severe agranulocytosis, 5 cases of severe liver damage, one case of anti-neutrophil cytoplasmic antibody (ANCA)-associated glomerulonephritis, and one case of vasculitis with small cutaneous ulcerations. Minor complications rates ranged between 2 and 36\%, though more complications were associated with higher doses and observed in children. The most reported adverse event was cutaneous reactions ( 74 cases); other adverse events were elevated liver enzymes (20 cases), leukocytopenia (11 cases), arthritis (9 cases), arthralgia (5 cases), myalgia (2 cases), thrombocytopenia (2 cases), fever ( 2 cases), nausea (1 case) and oral aphthous (1 case). In 19 patients, the ATD was discontinued because of adverse events. Only in 5 patients, adverse events were reported after the first year of treatment (Figure 1).

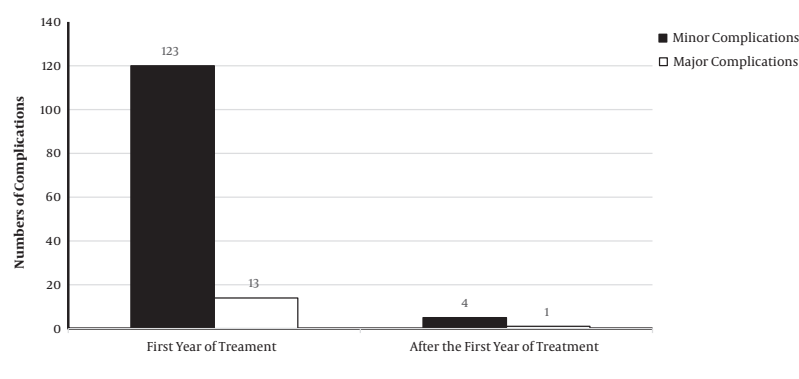

Figure 1. Relationship between time and antithyroid drugs complications

\subsubsection{Skin Reactions}

Minor cutaneous allergic reactions, such as rash, pruritis, and urticaria, are the most common adverse events, which usually arise within the first few weeks of treatment 
(27). In a meta-analysis that included 5,136 patients, rash was reported in $6 \%$ of the MMI and 3\% of the PTU users, whereas $2 \%$ - $3 \%$ of the patients had pruritis without rash (76). Another randomized trial described 22\% vs. 6\% cutaneous reactions in patients treated with $30 \mathrm{mg}$ vs. 15 mg MMI (27). About one-third of the patients, switching to the alternate ATD after developing minor reactions, developed minor adverse events (77). Current ATA guidelines recommend antihistamine therapy without stopping ATD in patients with mild skin reactions; in case of moderate reactions, definitive therapy or the alternate ATD is recommended, and in patients with more severe cutaneous reactions avoidance of all ATDs is recommended (21).

The majority of skin reactions occur in the first 3 months of treatment; the median time to occurrence of skin reactions is around 20 days (Table 2); occurrence after the second year of continuous ATD is rare.

\begin{tabular}{lc}
\hline Table 2. Time to Onset of Complications After the Initiation of Antithyroid Drugs ${ }^{\mathrm{a}}$ \\
\hline Complications & Time to Onset (Median) \\
\hline Skin reactions & 20 days \\
Hepatotoxicity & 30 days \\
Agranulocytosis & 50 days \\
Vasculitis & 3.5 Years \\
\hline
\end{tabular}

${ }^{a}$ Adopted from references 38, 60, 75-81

\subsubsection{Agranulocytosis}

Generally, agranulocytosis is defined as a granulocyte count $<500 / \mathrm{mm}^{3}$, but this rate is close to zero in the majority of the ATD-related agranulocytosis cases. The prevalence of agranulocytosis is about $0.2 \%-0.5 \%$ (78), mostly occurring within the first 90 days of treatment and is dosedependent (60). Also, agranulocytosis can develop after restarting the drug, even after a safe long-term drug usage (78). Presenting signs are the sudden onset of high fever, malaise, and severe pharyngitis (82). It has suggested that monitoring the white blood cell count could predict agranulocytosis, based on some studies indicating a gradual decrease in the granulocyte counts (78). The opponents emphasize the fact that this event is rare; usually, sudden onset and routine monitoring is not cost-effective (83). Nevertheless, the ATA guidelines cannot recommend either for or against routine white blood cell count monitoring because of insufficient evidence (21). Patients should be informed to stop treatment and contact their physicians if any concerning symptoms develop (84). Distressingly, a recent study alarmed that $61 \%$ of patients on ATDs were unfamiliar with these symptoms (85), calling attention to the importance of patient education, preferably in writing, and to emphasize this during follow-up (21). The treatment of ATD-induced agranulocytosis typically involves stopping the drug, supportive care, giving granulocyte colony-stimulating factor, and broad-spectrum antibiotics (86). Ongoing management of hyperthyroidism is a challenging choice between RAI and surgery.

The majority of agranulocytosis cases occur in the first 3 months of treatment; the median time to occurrence of agranulocytosis is around 50 days (Table 2); occurrence after the second year of continuous ATD is exceptional.

\subsubsection{Hepatotoxicity}

ATD-induced hepatotoxicity ranges from mild transaminase elevation to hepatic necrosis ensuing in death. In the United States, (from 1990 to 2007) 1 - 3 liver transplants from PTU exposure were reported annually to the FDA. In contrast, since 2009, there have been no reports of MMI-related deaths or liver transplants (87). Traditionally, injury of hepatocellular and cholestatic pattern has been described mostly with PTU and MMI, respectively (88). However, two large studies from Asia have challenged this classic idea $(79,80)$. In a study from Taiwan (79), 71,379 patients were newly prescribed ATDs and followed for a median of over 6 months. Hepatotoxicity was reported in $0.3 \%$ and $0.15 \%$ of the patients exposed to MMI and PTU, respectively. Non-infectious hepatitis was significantly higher with MMI than PTU (0.25\% vs. $0.08 \%$ ). Conversely, the rates of hepatic failure were higher with PTU than with MMI. The rates of cholestasis were similar between the two drugs. The second study from China (80) reported that among 90 patients with severe ATD-related hepatotoxicity, the majority (81\%) of cases of severe hepatotoxicity occurred within 12 weeks. The mean doses of MMI and PTU were approximately $20 \mathrm{mg}$ and $200 \mathrm{mg}$, respectively, and the patterns of hepatotoxicity (cholestatic vs hepatocellular injury pattern) were similar between the two drugs. Eventually, a Danish study reported similar rates of hepatic failure, at $0.03 \%$ of MMI and $0.05 \%$ of PTU users (89). Up to one-third of thyrotoxic patients had baseline transaminase elevation (90), and it is essential to test liver transaminase before starting ATD, and if it is over fivefold the upper limit of normal, ATD should be avoided. During ATD treatment, if further increases in liver transaminases from baseline elevation or any new increase ( $>$ three times the upper limit of normal) occurred, drug continuation should be reassessed (21). Serial measurements of the liver function test during ATD treatment were reported by $54 \%$ of respondents to a US-based survey of endocrinologists (91) and by $42 \%$ to a survey of European Thyroid Association Members (92); however, the potency of monitoring to distinguish early liver failure in this setting has not been evaluated. The 
ATA guidelines cannot recommend either for or against routine monitoring of the liver function tests in patients on ATDs but remarked that patients should be educated about potential hepatotoxicity and should stop treatment and contact their physicians if any symptoms of jaundice, malaise, dark urine or clay-colored stools developed (21).

Majority of hepatotoxicity cases occur in the first 3 months of treatment; the median time to occurrence of hepatotoxicity is around 50 days (Table 2); occurrence after the second year of continuous ATDs is unusual.

\subsubsection{Vasculitis}

ATD-induced lupus erythematosus was first described in 1970 (93). A recent study has discovered that such cases, drug-induced vasculitis, usually are associated with perinuclear anti-cytoplasmic neutrophil antibody (pANCA); and in contrast to other adverse events of ATD, they often happen after years of treatment (81) (Table 2). Puzzling the condition is the fact that ANCA positivity may occur in the absence of ATD in GD patients (94), as well as in patients treated with ATD who remain asymptomatic (95). Routine screening for ANCA positivity is not recommended (21).

Classic presentations are fever, malaise, and arthralgias. Patients might have clinical findings of cutaneous, pulmonary, and renal vasculitic involvement. Most cases are PTU users, children, and of Asian origin. The syndrome commonly improved after drug withdrawal, but some patients have required immunosuppressive therapy and hemodialysis (87).

\subsubsection{Arthralgias/arthritis}

Arthralgias sometimes occur during ATD treatment. Joint pain has been reported in $1.6 \%$ of the patients treated with ATD. These patients had severe arthralgias of the hands, shoulders, hips, knees, or ankles needing analgesic for 1-3 weeks for pain control. Joint swelling and erythema were uncommon (96).

\section{Conclusions}

Medical therapy of hyperthyroidism has been Astwood's gift to medicine. Although novel pharmacologic therapies that target the autoimmune basis of GD could be promising (97-99), these may be accessible in the coming years. Nowadays, in most parts of the world, ATDs are the first-line treatment for hyperthyroidism due to $\operatorname{GD}(58,92)$.

The main drawback of ATD treatment is the high relapse rate after drug discontinuation. Identification of the factors that could predict the recurrence of GD after ATD discontinuation is vital to make the best management decision in patients with the first episode of GD. Despite several studies trying to delineate these parameters, most of them have evaluated these determinants at the time of the ATD withdrawal and not the time of diagnosis. At an individual level, none of the possible risk factors for relapses has sufficient sensitivity and specificity to predict recurrences. Until larger multicenter cohorts are developed to make a perfect predicting model, the "GREAT score" could be appreciated.

On the other hand, ATD may have a favorable immunosuppressive effect, either primarily, to diminish thyroidspecific autoimmunity, or secondarily, as a result of controlling the hyperthyroid state. Taking these together accentuates the importance of maintaining patients in a euthyroid state for a long time to diminish autoimmunity and hyperthyroid relapse, which often calls for long-term use of methimazole, but at the lowest possible dose to minimize the risk of side effects.

Increasing evidence supports a positive relationship that can be suggested between the duration of ATD treatment and remission rate. Although some authors believe that recommendations for conventional ATD treatment for 12 - 18 months should be revised to a minimum of 5 years (100), so far we lack studies to determine the best treatment duration.

Growing evidence demonstrates that long-term ATD therapy has few adverse events, most of which occur within the initial months of treatment and in cases on larger doses. Hence, once we have reached the end of a conventional course of ATD treatment (12 - 18 months), the hazard is eliminated and adverse events are very rare to occur, demonstrating that by continuing low-dose ATD, we could maintain the patients' euthyroid state safely.

Considering the gaps in evidence, while waiting for larger future studies to answer our questions (who and how long should they be treated with ATD), we could suggest a longer term or even lifetime ATD treatment in selected patients.

\section{Acknowledgments}

The authors wish to acknowledge Ms. Niloofar Shiva for critical editing and syntax of the manuscript.

\section{Footnotes}

Authors' Contribution: Study concept and design: R.M., and F.A.; analysis and interpretation of data: R.M., and F.A.; drafting of the manuscript: R.M., and F.A.; critical revision of the manuscript for important intellectual content: R.M., and F.A.

Conflict of Interests: The authors declared no competing interests. 
Funding/Support: There is no related financial support.

\section{References}

1. Astwood EB. Chemotherapy of hyperthyroidism. Harvey lectures. 1945;40:195-235.

2. Astwood EB. Treatment of Hyperthyroidism with Thiourea and Thiouracil. Journal of the American Medical Association. 1943;122(2):78. doi: 10.1001/jama.1943.02840190008003.

3. Astwood EB. Landmark article May 8, 1943: Treatment of hyperthyroidism with thiourea and thiouracil. By E.B. Astwood. JAMA. 1984;251(13):1743-6. [PubMed: 6422063].

4. Astwood EB. The use of antithyroid drugs during pregnancy. $J$ Clin Endocrinol Metab. 1951;11(10):1045-56. doi: 10.1210/jcem-11-10-1045. [PubMed: 14873775].

5. Solomon DH, Beck JC, Vanderlaan WP. Prognosis of hyperthyroidism treated by antithyroid drugs. J Am Med Assoc. 1953;152(3):201-5. doi: 10.1001/jama.1953.03690030001001. [PubMed:13044497].

6. Hershman JM, Givens JR, Cassidy CE, Astwood EB. Long-term outcome of hyperthyroidism treated with antithyroid drugs. J Clin Endocrinol Metab. 1966;26(8):803-7. doi: 10.1210/jcem-26-8-803. [PubMed: 4162249].

7. Engler H, Taurog A, Dorris ML. Preferential inhibition of thyroxine and 3,5,3'-triiodothyronine formation by propylthiouracil and methylmercaptoimidazole in thyroid peroxidase-catalyzed iodination of thyroglobulin. Endocrinology. 1982;110(1):190-7. doi: 10.1210/endo-110-1-190. [PubMed: 7053983].

8. Visser TJ. Mechanism of inhibition of iodothyronine- $5^{\prime}$-deiodinase by thioureylenes and sulfite. Biochimica et Biophysica Acta (BBA)-Enzymology. 1980;611(2):371-8. doi: 10.1016/0005-2744(80)90074-1.

9. Astwood EB. Thyrotoxicosis. Baltimore: Williams \& Wilkins; 1967.

10. Mitsiades N, Poulaki V, Tseleni-Balafouta S, Chrousos GP, Koutras DA. Fas ligand expression in thyroid follicular cells from patients with thionamide-treated Graves' disease. Thyroid. 2000;10(7):527-32. doi: 10.1089/thy.2000.10.527. [PubMed:10958304].

11. Humar M, Dohrmann H, Stein P, Andriopoulos N, Goebel U, Roesslein $\mathrm{M}$, et al. Thionamides inhibit the transcription factor nuclear factorkappaB by suppression of Rac1 and inhibitor of kappaB kinase alpha. J Pharmacol Exp Ther. 2008;324(3):1037-44. doi: 10.1124/jpet.107.132407. [PubMed: 18055877].

12. Zantut-Wittmann DE, Tambascia MA, da Silva Trevisan MA, Pinto GA, Vassallo J. Antithyroid drugs inhibit in vivo HLA-DR expression in thyroid follicular cells in Graves' disease. Thyroid. 2001;11(6):575-80. doi: 10.1089/105072501750302886. [PubMed: 11442005].

13. Totterman TH, Karlsson FA, Bengtsson M, Mendel-Hartvig I. Induction of circulating activated suppressor-like T cells by methimazole therapy for Graves' disease. N Engl J Med. 1987;316(1):15-22. doi: 10.1056/NEJM198701013160104. [PubMed: 2946953].

14. Volpe R. The immunomodulatory effects of anti-thyroid drugs are mediated via actions on thyroid cells, affecting thyrocyteimmunocyte signalling: a review. Curr Pharm Des. 2001;7(6):451-60. doi: 10.2174/1381612013397898. [PubMed: 11281852].

15. Laurberg P. Remission of Graves' disease during anti-thyroid drug therapy. Time to reconsider the mechanism? Eur J Endocrinol. 2006;155(6):783-6. doi: 10.1530/eje.1.02295. [PubMed: 17132745].

16. Abalovich M, Llesuy S, Gutierrez S, Repetto M. Peripheral parameters of oxidative stress in Graves' disease: the effects of methimazole and 131 iodine treatments. Clin Endocrinol (Oxf). 2003;59(3):321-7. doi: 10.1046/j.1365-2265.2003.01850.x. [PubMed: 12919155].

17. Ademoglu E, Ozbey N, Erbil Y, Tanrikulu S, Barbaros U, Yanik BT, et al. Determination of oxidative stress in thyroid tissue and plasma of patients with Graves' disease. Eur J Intern Med. 2006;17(8):545-50. doi: 10.1016/j.ejim.2006.04.013. [PubMed: 17142172].

18. Wilson R, Buchanan L, Fraser WD, Jenkins C, Smith WE, Reglinski J, et al. Evidence for carbimazole as an antioxidant? Autoimmu- nity. 1998;27(3):149-53. doi: 10.3109/08916939809003862. [PubMed: 9609132].

19. Bianchi G, Solaroli E, Zaccheroni V, Grossi G, Bargossi AM, Melchionda $\mathrm{N}$, et al. Oxidative stress and anti-oxidant metabolites in patients with hyperthyroidism: effect of treatment. Horm Metab Res. 1999;31(11):620-4. doi: 10.1055/s-2007-978808. [PubMed:10598831].

20. Jansson R, Dahlberg PA, Lindstrom B. Comparative bioavailability of carbimazole and methimazole. Int J Clin Pharmacol Ther Toxicol. 1983;21(10):505-10. [PubMed: 6642787].

21. Ross DS, Burch HB, Cooper DS, Greenlee MC, Laurberg P, Maia AL, et al. 2016 American Thyroid Association Guidelines for Diagnosis and Management of Hyperthyroidism and Other Causes of Thyrotoxicosis. Thyroid.2016;26(10):1343-421. doi:10.1089/thy.2016.0229. [PubMed: 27521067].

22. Cooper DS. Antithyroid drugs in the management of patients with Graves' disease: an evidence-based approach to therapeutic controversies. J Clin Endocrinol Metab. 2003;88(8):3474-81. doi: 10.1210/jc.2003-030185. [PubMed:12915620].

23. Azizi F, Amouzegar A. Controversies in Management of Hyperthyroidism during Pregnancy. Arch Iran Med. 2017;20(10):657-8. [PubMed: 29137470].

24. Andersen SL, Olsen J, Wu CS, Laurberg P. Birth defects after early pregnancy use of antithyroid drugs: a Danish nationwide study. J Clin Endocrinol Metab. 2013;98(11):4373-81. doi: 10.1210/jc.2013-2831. [PubMed: 24151287].

25. Burch HB, Wartofsky L. Life-threatening thyrotoxicosis. Thyroid storm. Endocrinol Metab Clin North Am. 1993;22(2):263-77. [PubMed: 8325286].

26. Warnock AL, Cooper DS, Burch HB. Life-Threatening Thyrotoxicosis. In: Matfin G, editor. Endocrine and Metabolic Medical Emergencies: A Clinician's Guide. John Wiley \& Sons; 2018. p. 262-83. doi: 10.1002/9781119374800.ch16.

27. Nakamura H, Noh JY, Itoh K, Fukata S, Miyauchi A, Hamada N. Comparison of methimazole and propylthiouracil in patients with hyperthyroidism caused by Graves' disease. J Clin Endocrinol Metab. 2007;92(6):2157-62. doi: 10.1210/jc.2006-2135. [PubMed: 17389704].

28. Reinwein D, Benker G, Lazarus JH, Alexander WD. A prospective randomized trial of antithyroid drug dose in Graves' disease therapy. European Multicenter Study Group on Antithyroid Drug Treatment. J Clin Endocrinol Metab. 1993;76(6):1516-21. doi: 10.1210/jcem.76.6.8501160. [PubMed: 8501160].

29. Okamoto Y, Tanigawa S, Ishikawa K, Hamada N. TSH receptor antibody measurements and prediction of remission in Graves' disease patients treated with minimum maintenance doses of antithyroid drugs. Endocr J. 2006;53(4):467-72. doi: 10.1507/endocrj.k05-121. [PubMed: 16820704].

30. Vitti P, Rago T, Chiovato L, Pallini S, Santini F, Fiore E, et al. Clinical features of patients with Graves' disease undergoing remission after antithyroid drug treatment. Thyroid. 1997;7(3):369-75. doi: 10.1089/thy.1997.7.369. [PubMed: 9226205].

31. Laurberg P, Buchholtz Hansen PE, Iversen E, Eskjaer Jensen S, Weeke J. Goitre size and outcome of medical treatment of Graves' disease. Acta Endocrinol (Copenh).1986;111(1):39-43. doi: 10.1530/acta.0.1110039. [PubMed: 3753814].

32. Allahabadia A, Daykin J, Holder RL, Sheppard MC, Gough SC, Franklyn JA. Age and gender predict the outcome of treatment for Graves' hyperthyroidism. J Clin Endocrinol Metab. 2000;85(3):1038-42. doi: 10.1210/jcem.85.3.6430. [PubMed:10720036].

33. Nedrebo BG, Holm PI, Uhlving S, Sorheim JI, Skeie S, Eide GE, et al. Predictors of outcome and comparison of different drug regimens for the prevention of relapse in patients with Graves' disease. Eur J Endocrinol. 2002;147(5):583-9. doi: 10.1530/eje.0.1470583. [PubMed: 12444889].

34. Wang PW, Chen IY, Juo SH, Hsi E, Liu RT, Hsieh CJ. Genotype and phenotype predictors of relapse of graves' disease after antithyroid 
drug withdrawal. Eur Thyroid J. 2013;1(4):251-8. doi: 10.1159/000342621. [PubMed: 24783027]. [PubMed Central: PMC3821483].

35. Mohlin E, Filipsson Nystrom H, Eliasson M. Long-term prognosis after medical treatment of Graves' disease in a northern Swedish population 2000-2010. Eur J Endocrinol. 2014;170(3):419-27. doi: 10.1530/EJE-130811. [PubMed: 24366943].

36. Glinoer D, de Nayer P, Bex M, Belgian Collaborative Study Group on Graves D. Effects of l-thyroxine administration, TSH-receptor antibodies and smoking on the risk of recurrence in Graves' hyperthyroidism treated with antithyroid drugs: a double-blind prospective randomized study. Eur J Endocrinol. 2001;144(5):475-83. doi: 10.1530/eje.0.1440475. [PubMed: 11331213].

37. Kimball LE, Kulinskaya E, Brown B, Johnston C, Farid NR. Does smoking increase relapse rates in Graves' disease? J Endocrinol Invest. 2002;25(2):152-7. doi: 10.1007/BF03343979. [PubMed: 11929086].

38. Azizi F, Malboosbaf R. Long-Term Antithyroid Drug Treatment: A Systematic Review and Meta-Analysis. Thyroid. 2017;27(10):1223-31. doi: 10.1089/thy.2016.0652. [PubMed: 28699478]

39. Rotondi M, Cappelli C, Pirali B, Pirola I, Magri F, Fonte R, et al. The effect of pregnancy on subsequent relapse from Graves' disease after a successful course of antithyroid drug therapy.J Clin Endocrinol Metab. 2008;93(10):3985-8. doi: 10.1210/jc.2008-0966. [PubMed: 18664537].

40. Nakagawa Y, Mori K, Hoshikawa S, Yamamoto M, Ito S, Yoshida K. Postpartum recurrence of Graves' hyperthyroidism can be prevented by the continuation of antithyroid drugs during pregnancy. Clin Endocrinol(Oxf).2002;57(4):467-71. doi:10.1046/j.1365-2265.2002.01615.x. [PubMed: 12354128].

41. Anagnostis P, Adamidou F, Polyzos SA, Katergari S, Karathanasi E, Zouli C, et al. Predictors of long-term remission in patients with Graves' disease: a single center experience. Endocrine. 2013;44(2):44853. doi: 10.1007/s12020-013-9895-0. [PubMed: 23397523].

42. Leger J, Gelwane G, Kaguelidou F, Benmerad M, Alberti C, French Childhood Graves' Disease Study G. Positive impact of long-term antithyroid drug treatment on the outcome of children with Graves' disease: national long-term cohort study. J Clin Endocrinol Metab. 2012;97(1):110-9. doi: 10.1210/jc.2011-1944. [PubMed: 22031519].

43. Eckstein AK, Lax H, Losch C, Glowacka D, Plicht M, Mann K, et al. Patients with severe Graves' ophthalmopathy have a higher risk of relapsing hyperthyroidism and are unlikely to remain in remission. Clin Endocrinol (Oxf). 2007;67(4):607-12. doi: 10.1111/j.13652265.2007.02933.x. [PubMed: 17880407].

44. Vos XG, Endert E, Zwinderman AH, Tijssen JG, Wiersinga WM. Predicting the Risk of Recurrence Before the Start of Antithyroid Drug Therapy in Patients With Graves' Hyperthyroidism. J Clin Endocrinol Metab. 2016;101(4):1381-9. doi: 10.1210/jc.2015-3644. [PubMed: 26863422].

45. Piantanida E, Lai A, Sassi L, Gallo D, Spreafico E, Tanda ML, et al. Outcome Prediction of Treatment of Graves' Hyperthyroidism with Antithyroid Drugs. Horm Metab Res. 2015;47(10):767-72. doi: 10.1055/s0035-1555759. [PubMed: 26197855].

46. Struja T, Kaeslin M, Boesiger F, Jutzi R, Imahorn N, Kutz A, et al. External validation of the GREAT score to predict relapse risk in Graves' disease: results from a multicenter, retrospective study with 741 patients. Eur J Endocrinol. 2017;176(4):413-9. doi: 10.1530/EJE-16-0986. [PubMed: 28100628].

47. Masiello E, Veronesi G, Gallo D, Premoli P, Bianconi E, Rosetti S, et al. Antithyroid drug treatment for Graves' disease: baseline predictive models of relapse after treatment for a patient-tailored management. J Endocrinol Invest. 2018;41(12):1425-32. doi: 10.1007/s40618-018-0918-9. [PubMed: 29946800].

48. Effraimidis G. MANAGEMENT OF ENDOCRINE DISEASE: Predictive scores in autoimmune thyroid disease: are they useful? Eur J Endocrinol. 2019;181(3):R119-31. doi: 10.1530/EJE-19-0234. [PubMed: 31137010].

49. Abraham P, Avenell A, McGeoch SC, Clark LF, Bevan IS Antithyroid drug regimen for treating Graves' hyperthyroidism. Cochrane Database Syst Rev. 2010;(1). CD003420. doi:
10.1002/14651858.CD003420.pub4. [PubMed: 20091544]. [PubMed Central: PMC6599817].

50. Quadbeck B, Hoermann R, Roggenbuck U, Hahn S, Mann K, Janssen $\mathrm{OE}$, et al. Sensitive thyrotropin and thyrotropin-receptor antibody determinations one month after discontinuation of antithyroid drug treatment as predictors of relapse in Graves' disease. Thyroid. 2005;15(9):1047-54. doi: 10.1089/thy.2005.15.1047. [PubMed: 16187913].

51. Carella C, Mazziotti G, Sorvillo F, Piscopo M, Cioffi M, Pilla P, et al. Serum thyrotropin receptor antibodies concentrations in patients with Graves' disease before, at the end of methimazole treatment, and after drug withdrawal: evidence that the activity of thyrotropin receptor antibody and/or thyroid response modify during the observation period. Thyroid. 2006;16(3):295-302. doi: 10.1089/thy.2006.16.295. [PubMed: 16571093].

52. Kahaly GJ, Bartalena L, Hegedus L, Leenhardt L, Poppe K, Pearce SH. 2018 European Thyroid Association Guideline for the Management of Graves' Hyperthyroidism. Eur Thyroid J. 2018;7(4):16786. doi: 10.1159/000490384. [PubMed: 30283735]. [PubMed Central: PMC6140607].

53. Howard JE. Treatment of thyrotoxicosis. JAMA. 1967;202(8):706-9. [PubMed: 4168034].

54. Azizi F, Ataie L, Hedayati M, Mehrabi Y, Sheikholeslami F. Effect of long-term continuous methimazole treatment of hyperthyroidism: comparison with radioiodine. Eur J Endocrinol. 2005;152(5):695-701. doi: 10.1530/eje.1.01904. [PubMed: 15879354].

55. Azizi F, Yousefi V, Bahrainian A, Sheikholeslami F, Tohidi M, Mehrabi Y Long-term continuous methimazole or radioiodine treatment for hyperthyroidism. Arch Iran Med. 2012;15(8):477-84. [PubMed: 22827783].

56. Torring O, Watt T, Sjolin G, Bystrom K, Abraham-Nordling M, Calissendorff J, et al. Impaired Quality of Life After Radioiodine Therapy Compared to Antithyroid Drugs or Surgical Treatment for Graves' Hyperthyroidism: A Long-Term Follow-Up with the Thyroid-Related Patient-Reported Outcome Questionnaire and 36Item Short Form Health Status Survey. Thyroid. 2019;29(3):322-31. doi: 10.1089/thy.2018.0315. [PubMed: 30667296].

57. Kitahara CM, Berrington de Gonzalez A, Bouville A, Brill AB, Doody MM, Melo DR, et al. Association of Radioactive Iodine Treatment With Cancer Mortality in Patients With Hyperthyroidism.JAMA Intern Med. 2019. doi: 10.1001/jamainternmed.2019.0981. [PubMed: 31260066]. [PubMed Central: PMC6604114].

58. Brito JP, Schilz S, Singh Ospina N, Rodriguez-Gutierrez R, Maraka $S$, Sangaralingham LR, et al. Antithyroid Drugs-The Most Common Treatment for Graves' Disease in the United States: A Nationwide Population-Based Study. Thyroid. 2016;26(8):1144-5. doi: 10.1089/thy.2016.0222. [PubMed: 27267495].

59. Sato S, Noh JY, Sato S, Suzuki M, Yasuda S, Matsumoto M, et al. Comparison of efficacy and adverse effects between methimazole 15 mg+inorganic iodine $38 \mathrm{mg} /$ day and methimazole $30 \mathrm{mg} /$ day as initial therapy for Graves' disease patients with moderate to severe hyperthyroidism. Thyroid. 2015;25(1):43-50. doi: 10.1089/thy.2014.0084. [PubMed: 25178068].

60. Nakamura H, Miyauchi A, Miyawaki N, Imagawa J. Analysis of 754 cases of antithyroid drug-induced agranulocytosis over 30 years in Japan. J Clin Endocrinol Metab. 2013;98(12):4776-83. doi: 10.1210/jc.20132569. [PubMed: 24057289].

61. Laurberg P, Berman DC, Andersen S, Bulow Pedersen I. Sustained control of Graves' hyperthyroidism during long-term low-dose antithyroid drug therapy of patients with severe Graves' orbitopathy. Thyroid. 2011;21(9):951-6. doi: 10.1089/thy.2011.0039. [PubMed: 21834677].

62. Mazza E, Carlini M, Flecchia D, Blatto A, Zuccarini O, Gamba S, et al Long-term follow-up of patients with hyperthyroidism due to Graves' disease treated with methimazole. Comparison of usual treatment schedule with drug discontinuation vs continuous treatment with low methimazole doses: a retrospective study. J Endocrinol Invest 2008;31(10):866-72. doi: 10.1007/BF03346433. [PubMed: 19092290]. 
63. Bandai S, Okamura K, Fujikawa M, Sato K, Ikenoue H, Kitazono T. The long-term follow-up of patients with thionamide-treated Graves' hyperthyroidism. Endocr J. 2019;66(6):535-45. doi: 10.1507/endocrj.EJ180418. [PubMed: 30918165].

64. Glaser NS, Styne DM, Organization of Pediatric Endocrinologists of Northern California Collaborative Graves' Disease Study G. Predicting the likelihood of remission in children with Graves' disease: a prospective, multicenter study. Pediatrics. 2008;121(3):e481-8. doi: 10.1542/peds.2007-1535. [PubMed: 18267979].

65. Kaguelidou F, Alberti C, Castanet M, Guitteny MA, Czernichow P, Leger J, et al. Predictors of autoimmune hyperthyroidism relapse in children after discontinuation of antithyroid drug treatment. $J$ Clin Endocrinol Metab. 2008;93(10):3817-26. doi: 10.1210/jc.2008-0842. [PubMed: 18628515].

66. Azizi F, Amouzegar A. Management of thyrotoxicosis in children and adolescents: 35 years' experience in 304 patients. J Pediatr Endocrinol Metab. 2018;31(2):159-65. doi: 10.1515/jpem-2017-0394. [PubMed: 29306930].

67. Lippe BM, Landaw EM, Kaplan SA. Hyperthyroidism in children treated with long term medical therapy: twenty-five percent remission every two years. J Clin Endocrinol Metab. 1987;64(6):1241-5. doi: 10.1210/jcem-64-6-1241. [PubMed: 3571426].

68. Leger J, Carel JC. MANAGEMENT OF ENDOCRINE DISEASE: Arguments for the prolonged use of antithyroid drugs in children with Graves' disease. Eur J Endocrinol. 2017;177(2):R59-67. doi: 10.1530/EJE-16-0938. [PubMed: 28381452].

69. Villagelin D, Romaldini JH, Santos RB, Milkos AB, Ward LS. Outcomes in Relapsed Graves' Disease Patients Following Radioiodine or Prolonged Low Dose of Methimazole Treatment. Thyroid. 2015;25(12):128290. doi: 10.1089/thy.2015.0195. [PubMed: 26414885]

70. Azizi F, Takyar M, Madreseh E, Amouzegar A. Treatment of Toxic Multinodular Goiter: Comparison of Radioiodine and LongTerm Methimazole Treatment. Thyroid. 2019;29(5):625-30. doi: 10.1089/thy.2018.0397. [PubMed: 30803411].

71. Smith J, Brown RS. Persistence of thyrotropin (TSH) receptor antibodies in children and adolescents with Graves' disease treated using antithyroid medication. Thyroid. 2007;17(11):1103-7. doi: 10.1089/thy.2007.0072. [PubMed: 17822376].

72. Laurberg P, Wallin G, Tallstedt L, Abraham-Nordling M, Lundell G, Torring O. TSH-receptor autoimmunity in Graves' disease after therapy with anti-thyroid drugs, surgery, or radioiodine: a 5-year prospective randomized study. EurJEndocrinol.2008;158(1):69-75. doi:10.1530/EJE07-0450. [PubMed: 18166819].

73. Azizi F, Takyar M, Madreseh E, Amouzegar A. Long-term Methimazole Therapy in Juvenile Graves' Disease: A Randomized Trial. Pediatrics. 2019;143(5). doi: 10.1542/peds.2018-3034. [PubMed: 31040197].

74. Toft AD. Is long-term methimazole therapy as effective as radioiodine for treating hyperthyroidism? Nat Clin Pract Endocrinol Metab. 2005;1(1):14-5. doi: 10.1038/ncpendmet0019. [PubMed: 16929359].

75. Azizi F, Malboosbaf R. Safety of long-term antithyroid drug treatment? A systematic review. J Endocrinol Invest. 2019;42(11):1273-83. doi: 10.1007/s40618-019-01054-1. [PubMed: 31134536].

76. Sundaresh V, Brito JP, Wang Z, Prokop LJ, Stan MN, Murad MH, et al. Comparative effectiveness of therapies for Graves' hyperthyroidism: a systematic review and network meta-analysis. J Clin Endocrinol Metab.2013;98(9):3671-7.doi:10.1210/jc.2013-1954. [PubMed: 23824415]. [PubMed Central: PMC3763977].

77. Otsuka F, Noh JY, Chino T, Shimizu T, Mukasa K, Ito K, et al. Hepatotoxicity and cutaneous reactions after antithyroid drug administration. Clin Endocrinol (Oxf). 2012;77(2):310-5. doi: 10.1111/j.13652265.2012.04365.x. [PubMed: 22332800].

78. Tajiri J, Noguchi S, Murakami T, Murakami N. Antithyroid druginduced agranulocytosis. The usefulness of routine white blood cell count monitoring. Arch Intern Med. 1990;150(3):621-4. doi 10.1001/archinte.150.3.621. [PubMed: 2310281].

79. Wang MT, Lee WJ, Huang TY, Chu CL, Hsieh CH. Antithyroid drug-related hepatotoxicity in hyperthyroidism patients: a population-based cohort study. Br J Clin Pharmacol. 2014;78(3):61929. doi: 10.1111/bcp.12336. [PubMed: 25279406]. [PubMed Central: PMC4243912].

80. Yang J, Li LF, Xu Q, Zhang J, Weng WW, Zhu YJ, et al. Analysis of 90 cases of antithyroid drug-induced severe hepatotoxicity over 13 years in China. Thyroid. 2015;25(3):278-83. doi: 10.1089/thy.2014.0350. [PubMed: 25384184].

81. Balavoine AS, Glinoer D, Dubucquoi S, Wemeau JL. Antineutrophil Cytoplasmic Antibody-Positive Small-Vessel Vasculitis Associated with Antithyroid Drug Therapy: How Significant Is the Clinical Problem? Thyroid.2015;25(12):1273-81. doi:10.1089/thy.2014.0603. [PubMed: 26414658].

82. Kobayashi S, Noh JY, Mukasa K, Kunii Y, Watanabe N, Matsumoto M, et al. Characteristics of agranulocytosis as an adverse effect of antithyroid drugs in the second or later course of treatment. Thyroid. 2014;24(5):796-801. doi: 10.1089/thy.2013.0476. [PubMed: 24341564].

83. Sheng WH, Hung CC, Chen YC, Fang CT, Hsieh SM, Chang SC, et al. Antithyroid-drug-induced agranulocytosis complicated by life-threatening infections. QJM. 1999;92(8):455-61. doi: 10.1093/qjmed/92.8.455. [PubMed: 10627862].

84. Cooper DS. Antithyroid drugs. N Engl J Med. 2005;352(9):905-17. doi: 10.1056/NEJMra042972. [PubMed: 15745981].

85. Robinson J, Richardson M, Hickey J, James A, Pearce SH, Ball SG, et al. Patient knowledge of antithyroid drug-induced agranulocytosis. Eur Thyroid J. 2014;3(4):245-51. doi: 10.1159/000367990. [PubMed: 25759801]. [PubMed Central: PMC4311297].

86. Andres E, Zimmer J, Mecili M, Weitten T, Alt M, Maloisel F. Clinical presentation and management of drug-induced agranulocytosis. Expert Rev Hematol. 2011;4(2):143-51. doi: 10.1586/ehm.11.12. [PubMed: 21495924].

87. Cooper DS, Rivkees SA. Putting propylthiouracil in perspective. Clin Endocrinol Metab. 2009;94(6):1881-2. doi: 10.1210/jc.2009-0850. [PubMed: 19401361].

88. Woeber KA. Methimazole-induced hepatotoxicity. Endocr Pract. 2002;8(3):222-4. doi: 10.4158/EP.8.3.222. [PubMed: 12467281].

89. Andersen SL, Olsen J, Laurberg P. Antithyroid Drug Side Effects in the Population and in Pregnancy. I Clin Endocrinol Metab. 2016;101(4):1606-14. doi: 10.1210/jc.2015-4274. [PubMed: 26815881].

90. Huang MJ, Liaw YF. Clinical associations between thyroid and liver diseases. J Gastroenterol Hepatol. 1995;10(3):344-50. doi: 10.1111/j.14401746.1995.tb01106.x. [PubMed: 7548816].

91. Burch HB, Burman KD, Cooper DS. A 2011 survey of clinical practice patterns in the management of Graves' disease. J Clin Endocrinol Metab. 2012;97(12):4549-58. doi: 10.1210/jc.2012-2802. [PubMed: 23043191].

92. Bartalena L, Burch HB, Burman KD, Kahaly GJ. A 2013 European survey of clinical practice patterns in the management of Graves' disease. Clin Endocrinol (Oxf). 2016;84(1):115-20. doi:10.1111/cen.12688. [PubMed: 25581877]

93. Librik L, Sussman L, Bejar R, Clayton GW. Thyrotoxicosis and collagenlike disease in three sisters of American Indian extraction. $J$ Pediatr. 1970;76(1):64-8. doi: 10.1016/s0022-3476(70)80131-7. [PubMed: 4188531].

94. Guma M, Salinas I, Reverter JL, Roca J, Valls-Roc M, Juan M, et al. Frequency of antineutrophil cytoplasmic antibody in Graves' disease patients treated with methimazole. J Clin Endocrinol Metab. 2003;88(5):2141-6. doi: 10.1210/jc.2002-021383. [PubMed: 12727967].

95. Harper L, Chin L, Daykin J, Allahabadia A, Heward J, Gough SC, et al. Propylthiouracil and carbimazole associated-antineutrophil cytoplasmic antibodies (ANCA) in patients with Graves' disease. Clin Endocrinol (Oxf). 2004;60(6):671-5. doi: 10.1111/j.1365-2265.2004.02029.x. [PubMed: 15163328]

96. Shabtai R, Shapiro MS, Orenstein D, Taragan R, Shenkman L. The antithyroid arthritis syndrome reviewed. Arthritis Rheum. 
1984;27(2):227-9. doi: 10.1002/art.1780270216. [PubMed: 6199031].

97. Furmaniak J, Sanders J, Rees Smith B. Blocking type TSH receptor antibodies. Auto Immun Highlights. 2013;4(1):11-26. doi: 10.1007/s13317-0120028-1. [PubMed: 26000138]. [PubMed Central: PMC4389084].

98. Neumann S, Eliseeva E, McCoy JG, Napolitano G, Giuliani C, Monaco F, et al. A new small-molecule antagonist inhibits Graves' disease antibody activation of the TSH receptor. J Clin Endocrinol Metab. 2011;96(2):548-54. doi: 10.1210/jc.2010-1935. [PubMed: 21123444]. [PubMed Central: PMC3048317]
99. Pearce SHS, Dayan C, Wraith DC, Barrell K, Olive N, Jansson L, et al. Antigen-Specific Immunotherapy with Thyrotropin Receptor Peptides in Graves' Hyperthyroidism: A Phase I Study. Thyroid. 2019;29(7):1003-11. doi: 10.1089/thy.2019.0036. [PubMed: 31194638]. [PubMed Central: PMC6648194].

100. Azizi F, Abdi H. Toward Ultimate Care for Graves' Hyperthyroidism. Int J Endocrinol Metab. 2020;18(1). e98255. doi: 10.5812/ijem.98255. [PubMed: 32308699]. [PubMed Central: PMC7138596]. 